\title{
Investigation Experimental and Finite Element Method of Mechanical Properties of Hot Forging on Ti6Al4V Alloy
}

\author{
H. Tagimalek ${ }^{1 *}$, M. R. Maraki², M. Mahmoodi ${ }^{1}$, P. Mohammad Zadeh ${ }^{3}$ \\ ${ }^{1}$ Faculty of Mechanical Engineering, Semnan University, Semnan, Iran \\ 2 Department of Materials and Metallurgy Engineering, Birjand University of Technology, Birjand, Iran \\ ${ }^{3}$ Faculty of Mechanical Engineering, K.N. Toosi University of Technology, Tehran, Iran
}

\section{PAPER INFO}

\section{Paperhistory:}

Received 18 February 2021

Accepted in revised form 29 March 2021

\section{Keywords:}

DEFORM-3D

Finite element method

Hot forging

Mechanical properties

Ti6Al4V alloy

\section{$A B S T R A C T$}

Forging is one of the oldest and the most important processes of metal forming. The process occurs due to the waxy deformation of metal. In the forging process, the die walls control the material flow and the mechanical properties of the w orkpiece are significantly improved. Today's world industries, financing costs play a leading role in production. These categories have entered the industry to create a variety of simulation and numerical modeling methods to eliminate this problem. Simulation and experimental test, mechanical properties in the hot forging process in high-cost materials are of great interest to researchers. In this paper, the mechanical properties of hot forging in Ti6Al4V alloy are investigated. According to the obtained results, it can be found that a very close agreement has been made on experiments reported in literature and the simulation. Depending on the results, the strain rate Z-axis showed the shear bands appeared exactly on the 45-degree plates and in the sample center. In fact, the intersection of the band's sample center is the max strain applied to the die. This area has been created with an effective strain and stress at all depths of the workpiece and gradually expands.

doi: $10.5829 /$ ijee.2021.12.02.07

\section{INTRODUCTION}

The purpose of increasing the accuracy of metal forming processes was to produce deformed workpieces without defects and with the least consumption of materials and tool costs. In order to achieve this, accurate knowledge of material properties, process parameters, tools and surface behavior such as friction is required [1]. Alloys that contain both $\alpha$ and $\beta$ phases were called $\alpha+\beta$ titanium alloys [2]. Ti6Al4V alloy was the most widely used five grade $\alpha+\beta$ alloy [3]. Ti6Al4V alloy was usually used in annealed state or in solid and aged solution. Rapid quenching in solution was critical to achieving maximu $\mathrm{m}$ $\alpha+$ martensite phase deformation; which in turn increases the ability to age [4]. Ti6Al4V alloy can be hot worked by usual methods such as rolling, forging and severe plastic process (SPD). Usually, the work was done in the temperature range of $870 \sim 980{ }^{\circ} \mathrm{C}$ [5]. Hot deformation was widely used to make many products including fasteners, aircraft workpieces (turbine disks, blades gas turbine aircraft components, engine components, rocket clamps) and medical devices (medical and dental implants ) [6]. Bio-compatibility of Ti6A14V alloy is excellent, especially when direct contact with tissue or bone was considered [7].

Forging was one of the oldest and most important metal forming processes due to the waxy deformation of metal [8]. In the forging process, the die walls control the flow of materials, the mechanical properties of the workpiece were significantly improved [9]. The design of forged dies requires a lot of knowledge about the properties of strength, sensitivity to deformation rate and temperature, friction and workpiece shape that the distortion of the die under special loads in the production of workpieces with low force was significant [10]. The choice of die material depends on factors such as die

\footnotetext{
*Corresponding Author Email: h_tagimalek@semnan.ac.ir (H. Tagimalek)
} 
dimensions, workpiece composition and properties, workpiece complexity, forging temperature, type of forging process and die material cost [11]. Heat transfer from the hot workpiece to the die was also an important factor. Materials that were commonly used in the manufacture of forging dies can be referred to steels with material as $\mathrm{Cr}, \mathrm{Ni}$, Mo and $\mathrm{V}$ [12].

Zhao et al. [13] studied on the evolution of microstructure by hot forging on steel, $\mathrm{Ti}$ and $\mathrm{Al}$. In their study, they investigated microstructure improvements at 650 950 ${ }^{\circ} \mathrm{C}$ at constant strain rates. Due to the fact that the phase transition temperature of cast irons is in the range of $750 \sim 800{ }^{\circ} \mathrm{C}$ and was brittle; the initial deformation mechanism includes the decomposition of the multi-layer structure and the twin deformation at 900 ${ }^{\circ} \mathrm{C}$. They found that under different conditions the strain rate of the phase shapes and the heterogeneous microstructure significantly affect the mechanical properties of the solid-state phase. Chen et al. [14] have studied the structural evolution and its changes in the hot forging process. During this study, they found that in order to achieve a stable and layered microstructure of Ti43A19VY alloy, the existing structure must be replaced without any changes. The effect of purification was mainly related to fixed microstructures, especially for granulation, grain size and workpiece remaining after process passes. In a number of studied samples, martensite sheets were produced in dense and coarse dense form with increasing grain size due to decreasing cooling rate during the submerged sample. So that in the sample and experiment that have used a special type of coolant, grain size up to about $25 \sim 50 \mu \mathrm{m}$ have been achieved. Luo et al. [15] investigated on the effect of friction conditions on structural properties in the hot forging process of Ti6Al4V turbine blade. The results showed that friction had a significant effect on the microstructures of $\mathrm{Ti}$ workpieces and further affects their mechanical properties. Certain conditions of oil cooling are reduced by creating the least amount of available phases with a volume fraction. However, under normal conditions, it reduces the average values of temperature and phase volume fractions as well as the uniformity of distribution to a minimum. Zhou et al. [16] investigated the microstructural behavior and microstructural evolution in hot forging by compression with Ti44Al8Nb- (W, B, Y). Dispersion efficiencies in the range of $0.12,0.25$ and 0.5 and the activation energy of the subjects were recognized as important. The results indicate that the microstructural evolution depends on temperature and strain rate. In addition, the recovery and recrystallization of the phases as well as the spheroidization of the phases play important roles in improving the microstructure. The parameters selected for the secondary hot work are about $1150{ }^{\circ} \mathrm{C}$ with a strain rate of less than 0.25 with a pressure of 0.5 . The hot work pass can expand with less-pressure and higher strain rate. Finally, Non-cracked Ti-Al alloy sheets were successfully produced by hotrolled. The prepared sheet has a good flexibility at room temperature with a grain size of an average of $10 \mu \mathrm{m}$.

In this paper, the mechanical properties of hot forging on Ti6Al4V alloy with experimental and finite element (FE) are investigated. The importance of doing this article is the widespread use of Ti6A14V alloy in applied and military industries. Figure 1 shows a schematic of the hot forging process.

\section{MATERIAL AND METHOD}

In the study, SANTAM-STD 1000 industrial press, has been illustrated. Press consisted of 150-ton capacity and $300 \mathrm{~mm}$ effective stroke driven by a hydraulic power pack. It also equipped to feedback system with digital ruler and precision of $0.1 \%$ to read displacement values. Velocity of the piston movement is adjustable varying between 0.01 and $150 \mathrm{~mm} / \mathrm{min}$. Some experiments were replicated to obtain the more reliable findings. In this study, Ti6Al4V alloy was used as sample of the cylindrical for tests. Current forging process was carried out in hot conditions.

The experimental system applied in this study is shown in Figure 2.

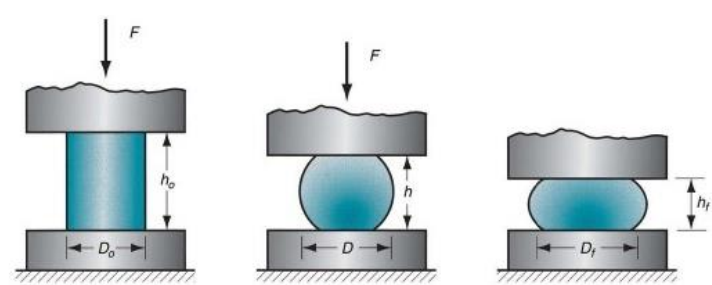

Figure 1. Schematic of hot forging process
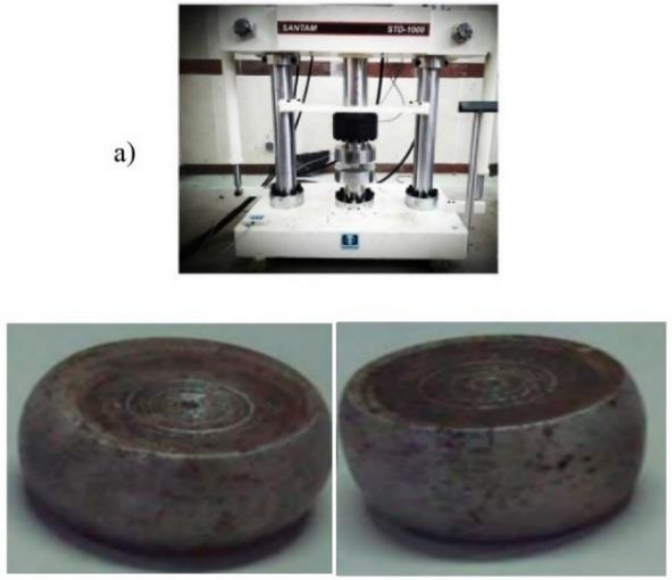

b)

Figure 2. Experimental sy stem applied in the current study; a) deformation system, b) experimentally sample 


\section{FINITE ELEMENT SIMULATION}

The purpose of this study was to obtain the optimal range of parameters in the hot forging process to facilitate the design and fabrication of the die, as well as its simulation and analysis. For this purpose, DEFORM-3D software was used for simulation. The top and bottom die (rigid and is othermal) and the Ti6Al4V sample were considered to be Elastic-Plastic. Figure 3 shows a cylindrical sample with a diameter of $50 \mathrm{~mm}$ and a height of $1000 \mathrm{~mm}$, with plastic behavior of Ti6A14V alloy; was selected and 20,000 triangular meshes were used for meshing the sample. The type of meshing was examined according to the law of vertex-to-vertex and 1:1. Samples were performed during simulation of processes in laboratory and workshop at room-temperature, Coulomb friction coefficient equal to 3.0 and mandrel speed of $5 \mathrm{~mm} \cdot \mathrm{s}^{-1}$. To prevent decentralization, 45-degree chamfer stress was created on the simulated sample. Figure 4 shows a schematic of the hot forging process in the final-step. Material behavior according to yield stress (YS) was defined as a function of effective plastic strain, effective plastic strain rate and temperature based on literature [5]. The desired material was selected from the software library and then the parameters related to the material, which include parameters such as Poisson's coefficient, thermal conductivity, hardness, etc. were defined.

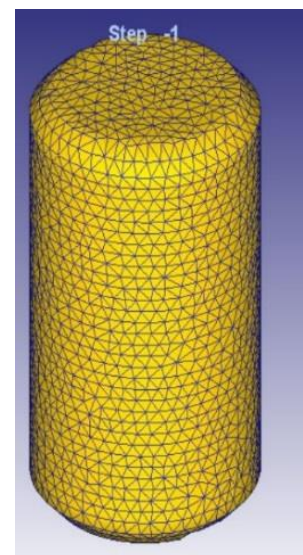

Figure 3. Image sample of mesh cylinders at hot forging process

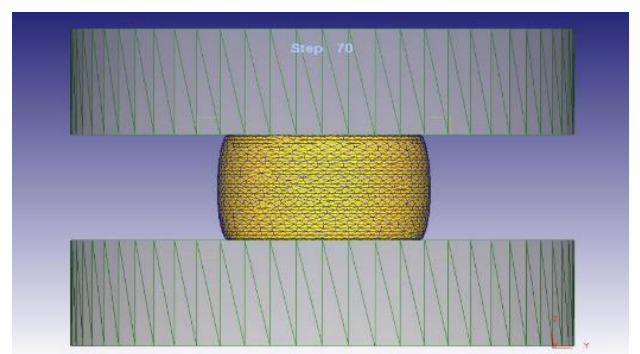

Figure 4. Illustration of FEM model for hot forging process in the final-step
To obtain the optimal size for mesh, the effect of element size on changes in equivalent plastic strain was investigated. In Figure 5, it was observed that after the mesh size of 1 , the smaller the size mesh, the less impact they have on the PEEQ and strain of the plastic. So the mesh size of 1 was used to simulate the sheet. Figure 5 shows the effect of changing the mesh size on the variable strain changes from the sample center.

\section{DISCUSSION AND RESULTS}

The results of the hot forging process were performed on Ti alloy using FE. The results were evaluated on cylindrical dimensions with a diameter of $50 \mathrm{~mm}$ and a height of $1000 \mathrm{~mm}$. According to the surfaces of the simulated workpieces Non-lubrication, it is possible to see the original inner and outer edge of the workpiece, which did not show any flow.

The strain rate along the $\mathrm{X}, \mathrm{Y}$ and $\mathrm{Z}$-axis using curves of Figure 6 showed the shear bands appeared exactly on the 45-degree plates and in the sample center. In fact, the intersection of the band's sample center is the max strain applied to the die. Figures 7 and 8 confirms that this area has been created with an effective strain and stress at all depths of the workpiece and gradually expands.

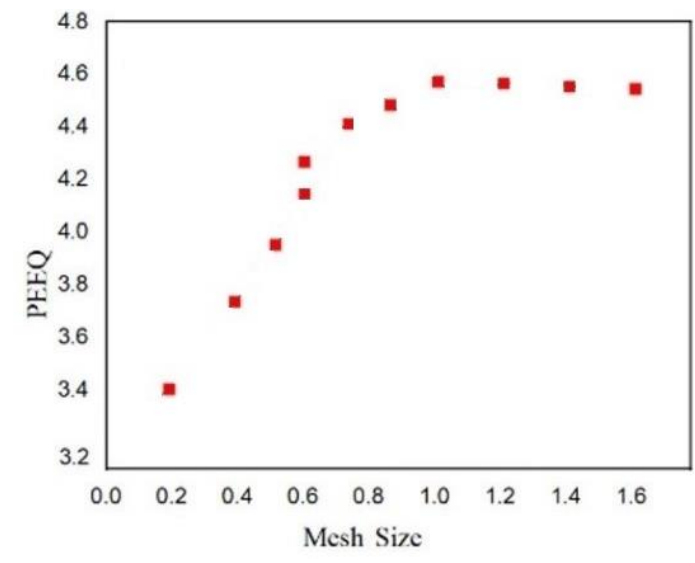

Figure 5. Mesh sensitivity diagram

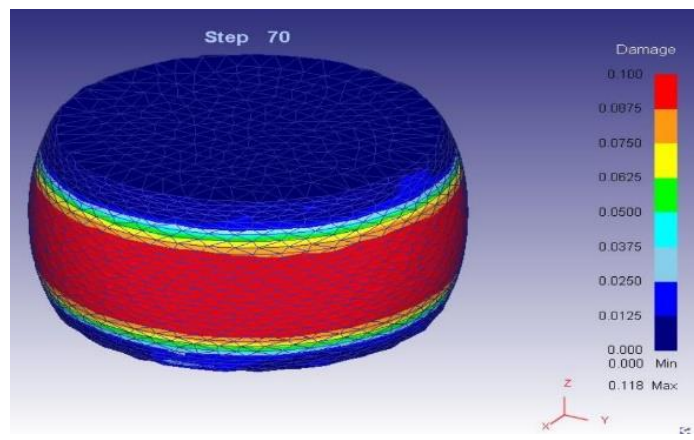

Figure 6. Damage obtained at final-step 


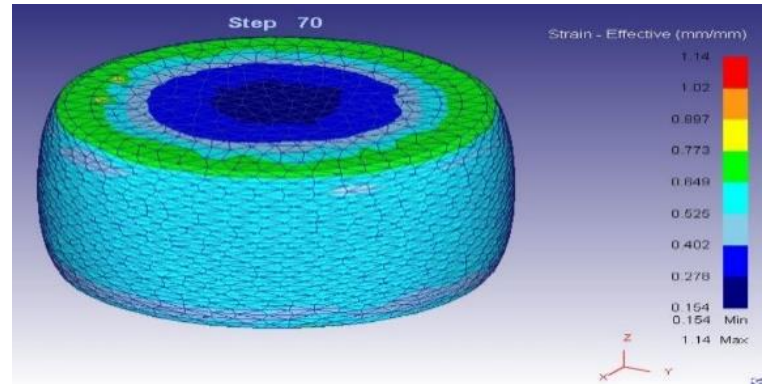

Figure 7. Effective strain obtained at final-step

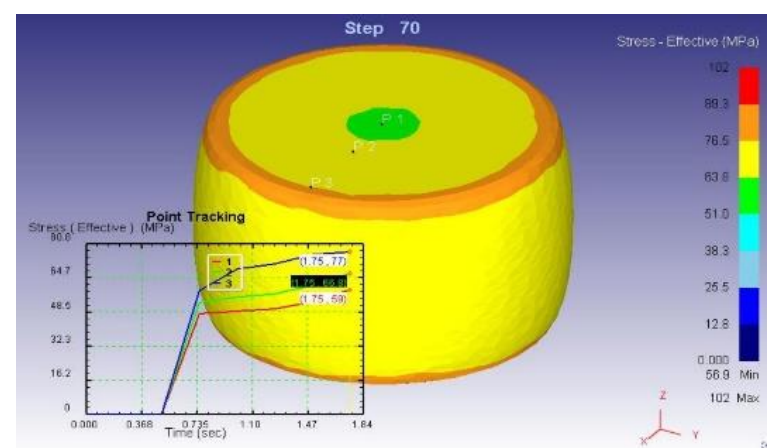

Figure 8. Effective stress obtained at final-step at the points defined

According to Figure 9, the amount of strain on the upperand lower levels of the final-workpiece towards the outer edges is higher than other workpieces. At the high and low levels towards the inner edges, the amount of strain is high. Obviously, in that workpiece of the finalsurface of the workpieces that are in contact with the die, the amount of strain is low. Because of the friction between the workpiece and die does not allow it to slip on that workpiece of the die.

Also, the mean effective strains calculated along the $\mathrm{X}$ and $\mathrm{Z}$-axis obtained from the simulation, which are a good representation of all surface points. The forging process approaching the center of the sample, the area is seen more finely with higher strain, i.e. the distribution of strain in workpieces several samples are different. The

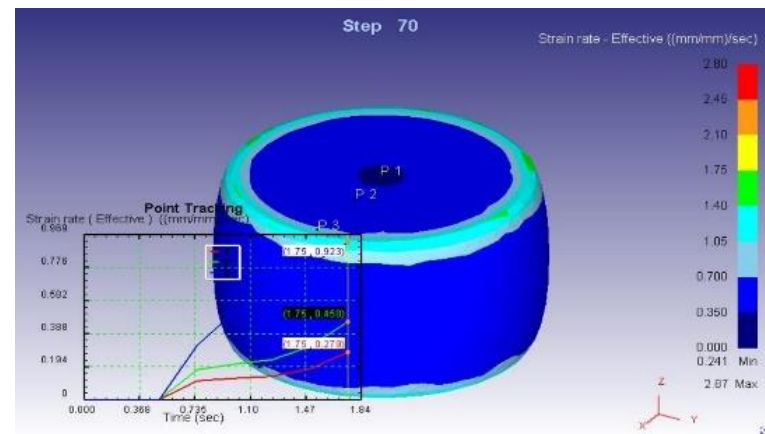

Figure 9. Effective strain rate obtained at final-step at the points defined reason that more strain is obtained in the center area should be representative of hardness. In Figure 10, the material on both sides of these edges in the final workpiece is due to the material flow from the inside of the workpiece to the surfaces.

Figure 11 shows the velocity of the material in different workpieces, with the red arrows showing the velocity of the material at about $4 \mathrm{~mm} / \mathrm{s}$. As it is known, in different workpieces of the material flow, it has different velocities and different directions, which is effective in the distribution of granulation. The velocity applied to the material in the direction of the $\mathrm{Z}$-axis and the fluidity of matter is also done in the direction of the $\mathrm{X}, \mathrm{Y}$-axis. The process of strain distribution in the $\mathrm{X}$ and $\mathrm{Z}$-axis increase as they approach the center of the sample and as they move away from the center is reduced. While in the direction of the Y-axis has an almost constant value.

\section{VALIDETION FEM AND EXPERIMENTAL}

Figure 12 shows the force in the sample comparing the experimental and simulation results. It declares that forging force is almost the same for both numerical and

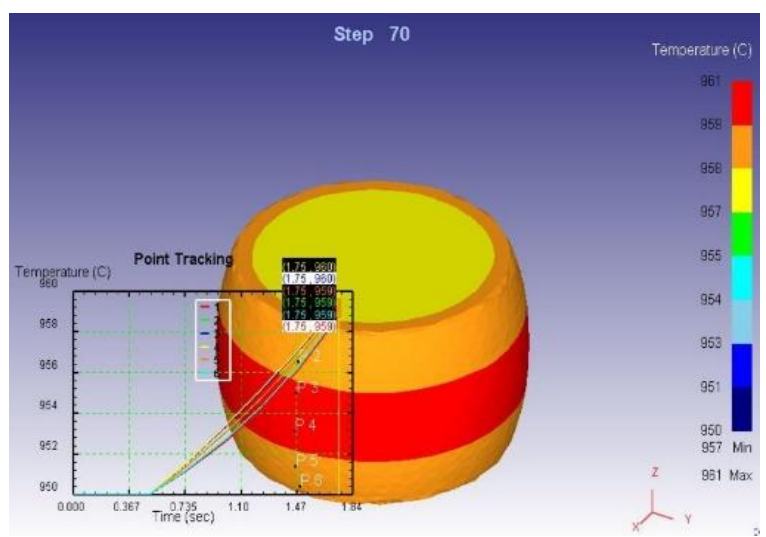

Figure 10. Temperature changes obtained at final-step at the points defined

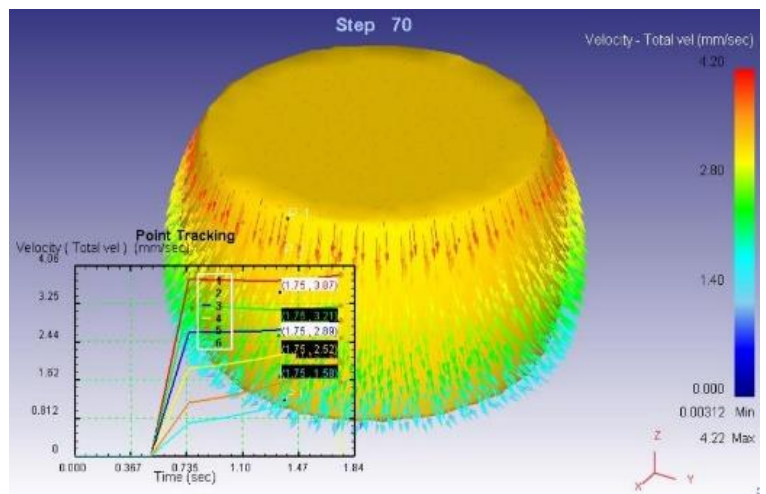

Figure 11. Investigation of material flow obtained at finalstep at the points defined 


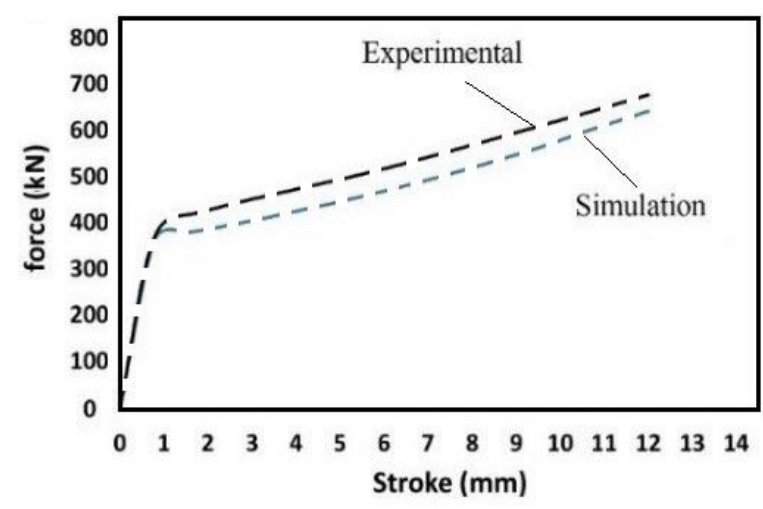

Figure 12. Validation of two forging force diagrams obtained from the experimental test and the simulation

experimental studies in the first stages, the experimental force coincidences well with the experimental one; however, as the process goes on, the experimental curve exceeds the numerical one at the distance of about $1 \mathrm{~mm}$ and reaching the maximum difference of $10 \%$ at the end of the distant. The reason of this behavior is due to the fact that, the as-received material porosities and metallurgical defects causing easy deformation at the first-step of the forging ratio the final-step.

\section{CONCLUSION}

Investigation of mechanical properties of hot open forging on Ti6A14V alloy was performed using experimental and finite element method. The values obtained were completely consistent with the results of experimental experiments of other researchers.

- Using the deformation software, the input parameters can be simulated in the software before making the template, and by examining the defects created and changing the parameters and obtaining the best effective parameters in the process, the operation cycle can be optimized.

- Obtaining the diagrams mentioned above, examined the problems and sensitive or weak areas, and if the results were complete and accurate, proceeded to construct the die and perform the process.

- The strain rate along the $\mathrm{X}, \mathrm{Y}$ and $\mathrm{Z}$ axis using the shearbands appeared exactly on the 45-degree plates and in the sample center. In fact, the intersection of the band's sample center is the max strain applied to the die experimental and finite element method confirms that this area has been created with an effective strain and stress at all depths of the workpiece and gradually expands.

- Using proper lubrication and smoothness of the die surface can improve the operation and improve the flow of materials.

- To prevent the common defects of the forging process, the sample should be performed in several steps to prevent defects and wear die. The main problem of the hot process is the max of stress workpiece, which must be solved by examining the diagrams and distributing the stress using heat treatment, as well as possible defects such as cracks in the corners and edges by microscopic magnification and tests. Relevant check and finally fix.

\section{AUTHOR CONTRIBUTIONS}

Tagimalek (45\%) planned the scheme, initiated the project, and suggested the experiments; Tagimalek and Maraki $(25 \%)$ conducted the experiments and analyzed the empirical and simulation results; Mahmoodi (20\%) and Mohammadzadeh (10\%) developed the mathematical modeling and examined the theory validation. The manuscript was written through the contribution of all authors. All authors discussed the results, reviewed and approved the final version of the manuscript.

\section{ACKNOWLEDGMENTS}

The authors are very much thankful to the unknown reviewers for their valuable and constructive suggestions which improved the readability of the paper.

\section{FUNDING}

The authors received no financial support for the research, authorship, and publication of this article.

\section{REFERENCES}

1. Tagimalek, H., Maraki, M. R., Mahmoodi, M., and Azargoman, M. 2020. "A Hybrid SVM-RVM Algorithm to Mechanical Properties in the Friction Stir Welding Process." Journal of Applied and Computational https://doi.org/10.22055/JACM.2019.31017.1811

2. Maraki, M.R., Tagimalek, H., Azargoman, M., Khatami, H. and Mahmoodi, M. 2020. "Experimental Investigation and Statistical Modeling of the Effective Parameters in Charpy Impact Test on AZ31 Magnesium Alloy with V-shape Groove Using Taguchi Method." International Journal of Engineering, Transactions $C$ : Aspects, 33(12), pp.2521-2529. https://doi.org/10.5829/ije.2020.33.12c.13

3. T sai, M.-T., Chen, Y.-W., Chao, C.-Y., Jang, J. S. C., T sai, C.-C., Su, Y.-L., and Kuo, C.-N. 2020. "Heat-treatment effects on mechanical properties and microstructure evolution of Ti-6Al-4V alloy fabricated by laser powder bed fusion." Journal of Alloys and Compounds, 816, pp.152615. https://doi.org/10.1016/j.jallcom.2019.152615

4. Zhang, M., Zhang, D., Geng, D., Liu, J., Shao, Z., and Jiang, X. 2020 . "Surface and sub-surface analysis of rotary ultrasonic elliptical end milling of Ti-6Al-4V." Materials \& Design, 191, pp.108658. https://doi.org/10.1016/j.matdes.2020.108658

5. Arısoy, Y. M., and Özel, T. 2015. "Prediction of machining induced 
microstructure in $\mathrm{Ti}-6 \mathrm{Al}-4 \mathrm{~V}$ alloy using $3-\mathrm{D}$ FE-based simulations: Effects of tool micro-geometry, coating and cutting conditions." Journal of Materials Processing Technology, 220, pp.1-26. https://doi.org/10.1016/j.jmatprotec.2014.11.002

6. Hsu, C.-C., Chiu, H.-Y., Liao, C.-C., and Fuh, Y.-K. 2020. "An investigation on deformation mechanism of non-standard gear teeth forming in the hot impression forging of multicore cable cutter." Journal of Manufacturing Processes, 54, pp.158-168. https://doi.org/10.1016/j.jmapro.2019.11.019

7. Zhao, J., Deng, Y., Zhang, J., and T ang, J. 2019. "Effect of forging speed on the formability, microstructure and mechanical properties of isothermal precision forged of $\mathrm{Al}-\mathrm{Zn}-\mathrm{Mg}-\mathrm{Cu}$ alloy." Materials Science and Engineering: A, 767, pp.138366. https://doi.org/10.1016/j.msea.2019.138366

8. Wolfgarten, M., Rudolph, F., and Hirt, G. 2020. "Analysis of process forces and geometrical correlations for open-die forging with superimposed manipulator displacements." Journal of Materials Processing Technology, 276, pp.116408. https://doi.org/10.1016/j.jmatprotec.2019.116408

9. Wang, Z., Hui, W., Chen, Z., Zhang, Y., and Zhao, X. 2020. "Effect of vanadium on microstructure and mechanical properties of bainitic forging steel." Materials Science and Engineering: A, 771, pp.138653. https://doi.org/10.1016/j.msea.2019.138653

10. Lee, J. K., Kwon, S.-C., Jeong, H.-T., Han, S.-H., and Park, S. H. 2020. "Fabrication of very-high-strength pure copper with fine grain structure through multi-axial diagonal forging." Materials Letters, 269, pp.127663. https://doi.org/10.1016/j.matlet.2020.127663

11. Skryabina, N., Aptukov, V., de Rango, P., and Fruchart, D. 2020
"Effect of temperature on fast forging process of $\mathrm{Mg}-\mathrm{Ni}$ samples for fast formation of Mg2Ni for hydrogen storage." International Journal of Hydrogen Energy, 45(4), pp.3008-3015. https://doi.org/10.1016/j.jhydene.2019.11.157

12. Niu, H. Z., Kong, F. T., Chen, Y. Y., and Yang, F. 2011 "Microstructure characterization and tensile properties of $\beta$ phase containing TiAl pancake." Journal of Alloys and Compounds, 509(42), https://doi.org/10.1016/j.jallcom.2011.08.078 pp.10179-10184.

13. Zhao, Y. B., Zhang, S. Z., Zhang, C. J., Lin, P., Hou, Z. P., and Chen, Y. Y. 2016. "Microstructural evolution of hot-forged high $\mathrm{Nb}$ containing TiAl alloy during high temperature tension." Materials Science and Engineering: A, 678, pp.116-121. https://doi.org/10.1016/j.msea.2016.09.095

14. Chen, L., Lin, J., Xu, X., Chen, Y., Kong, F., and Liang, Y. 2019. "Microstructural evolution and refinement of as-forged Ti-43Al$9 \mathrm{~V}-\mathrm{Y}$ alloy after quenching and tempering." Intermetallics, 113, pp.106576. https://doi.org/10.1016/j.intermet.2019.106576

15. Luo, S., Wang, Q., Zhang, P., Li, J., and Liu, Q. 2020. "Effect of friction conditions on phase transformation characteristics in hot forging process of Ti-6Al-4 Vturbine blade." Journalof Materials Research and Technology, 9(2), pp.2107-2115. https://doi.org/10.1016/j.jmrt.2019.12.041

16. Zhou, H., Kong, F., Wang, X., and Chen, Y. 2017. "Hot deformation behavior and microstructural evolution of as-forged Ti-44Al-8Nb-(W, B, Y) alloy with nearly lamellar microstructure." Intermetallics, $81, \quad$ pp.62-72. https://doi.org/10.1016/j.intermet.2017.02.026

\section{COPYRIGHTS}

(C2021 The author(s). This is an open access article distributed under the terms of the Creative Commons Attribution (CC BY 4.0), which permits unrestricted use, distribution, and reproduction in any medium, as long as the original authors and source are cited. No permission is required from the authors or the publishers.

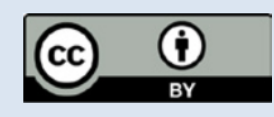

فورج يكى از قديمىترين و مهمترين فرآيندهاى تشكيل فلز است. اين فرآيند به دليل تغيير شكل مومى فلز اتفاق مىافتد. در فرآيند فورج، ديوارههاى قالب

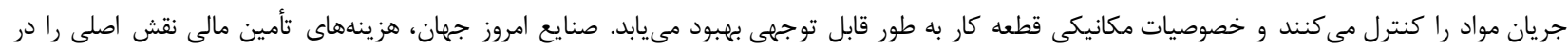

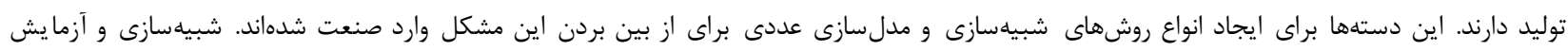

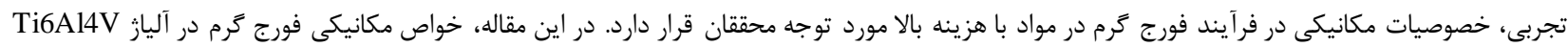

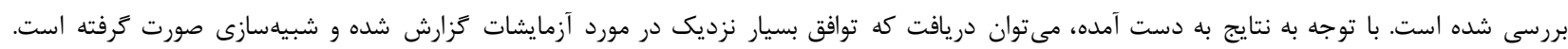

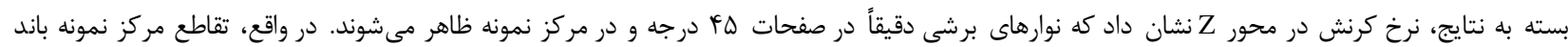

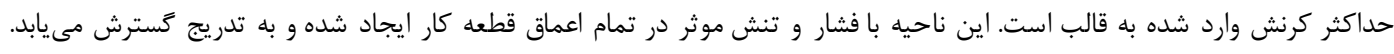

